1. Egan BM, Kjeldsen SE, Grassi G, Esler M, Mancia G. The global burden of hypertension exceeds 1.4 billion people: should a systolic blood pressure target below 130 become the universal standard? 2019;37(6):1148-1153. doi:10.1097/hjh.0000000000002021

2. Huỳnh Văn Minh, Nguyển lân Việt. Blood pressure screening during the May Measurement Month 2017 programme in Vietnam-South-East Asia and Australasia. Eur Heart J Suppl. Apr 2019;21(Suppl doi:10.1093/eurheartj/suz076

3. Redon J, Tellez-Plaza M, Orozco-Beltran D, et al. Impact of hypertension on mortality and cardiovascular disease burden in patients with cardiovascular risk factors from a general practice setting: the ESCARVAL-risk study. J Hypertens. Jun 2016;34(6):1075-83. doi: $10.1097 / \mathrm{HJH} .0000000000000930$

4. Ettehad D, Emdin CA, Kiran A, et al. Blood pressure lowering for prevention of cardiovascular disease and death: a systematic review and metaanalysis. Lancet. Mar 5 2016;387(10022):957-967. doi:10.1016/S0140-6736(15)01225-8

5. Legido-Quigley $H$, Camacho Lopez PA, Balabanova D, et al. Patients' knowledge, attitudes, behaviour and health care experiences on the prevention, detection, management and control of hypertension in Colombia: a qualitative study. PLoS One. 2015;10(4):e0122112. doi:10.1371/journal.pone.0122112

6. Nguyễn Lân Việt. Phòng chống tăng huyết ápGiảm gánh nặng bênh tật. Dự án phòng, chống bênh tim mạch- Chương trình mục tiêu Quốc gia về y tế. 2011;

7. Tổng Hôi $\mathbf{Y}$ hoc Viêt Nam, Bô $\mathbf{Y}$ Tế. Hôi nghi Khoa hơc toàn quốc lần thứ VỉI-2017, chủ đề phòng chống các bênh không lây nhiếm. Bô Y Tế. Accessed 12/9, 2021. https://moh.gov.vn/tin-lienquan/-/asset_publisher/vjYyM709aWnX/ content/hoi-nghi-khoa-hoc-toan-quoc-lan-thu-vii2017-chu-e-phong-chong-cac-benh-khong-laynhiem?inheritRedirect $=$ false

8. Hội Tim mạch học Quốc gia Việt Nam. Khuyến cáo về chẩn đoán và điểu trị tăng huyết áp Accessed 15/8, 2021. http://vnha.org.vn/data/ Khuyen-Cao-THA-2018.pdf

9. Pham Thái Sơn, Nguyễn Ngọ Quang Nguyễn Lân Việt, et al. Prevalence, awareness, treatment and control of hypertension in Vietnamresults from a national survey. J Hum Hypertens. Apr 2012;26(4):268-80. doi:10.1038/jhh.2011.18

\title{
NGHIÊN CỨU HOÀN THIỆN YOGA TRI LIỆU VIẸT NAM ĐỂ PHỤC HỒI CHỨC NĂNG CHO BẸNH NHÂN DI CHỨNG TAI BIẾN MACH MÁU NÃO TẠI BỆNH VIÊ̂N ĐA KHOA THÀNH PHỐ HÀ TĨNH
}

\author{
Trần Nguyên Phú ${ }^{1}$, Võ Thị Trang ${ }^{1}$, Hoàng Ngọc Hà ${ }^{1}$, \\ Đặng Hùng ${ }^{2}$, Lê Thị Huyền Trang ${ }^{1}$, Lê Thị Thanh Thủy ${ }^{1}$, \\ Ngô Thị Thúy Diễn', Nguyễn Thị Mỹ Trang1, \\ Trần Thị Ngọc ${ }^{1}$, Nguyễn Sử Minh Ngọc'
}

\section{TÓM TẮT}

Nghiên cứu thử nghiệm lâm sàng ngẫu nhiên có đối chứng trên 2 nhóm người bênh nhằm đánh giá kết quả phương pháp Yoga trị liệu Việt Nam phục hồi chức năng (PHCN) người bệnh tai biến mạch máu não (TBMMN). 80 người bệnh di chứng TBMMN đã được điều trị giai đoạn cấp ổn định, tuổi từ $40-75$ tuổi, không phân biệt giới tính, nghề nghiệp, tình nguyên tham gia nghiên cứu. 40 người bệnh nhóm nghiên cứu phuc hồi chức năng bằng phương pháp Yoga trị liêu Việt Nam, nhóm đối chứng điêu trị PHCN thông thường. Kết quả được so sánh sau 90 ngày điêu trị cho thấy $75 \%$ người bệnh ở nhóm can thiệp giảm 2 mức độ liệt trở lên, tỳ lệ này ở nhóm đối chứng là 42,5\%

\footnotetext{
${ }^{1}$ Bệnh viện Đa khoa thành phố Hà Tïnh

2 Học viện Yoga Việt Nam

Chiu trách nhiệm chính: Trần Nguyên Phú

Email: Trannguyenphu@gmail.com

Ngày nhận bài: 13.9.2021

Ngày phản biện khoa học: 2.11 .2021

Ngày duyệt bài: 15.11.2021
}

$(p<0,05)$. Ngoài ra huyết áp, sức khỏe tinh thần, mức độ độc lập trong sinh hoạt hằng ngày, nguy cơ té ngã cải thiên tốt hơn có ý nghĩa thống kê so với trước khi điều trị và nhóm đối chứng.

Tư khóa: tai biến mạch máu não, yoga, yoga trị liệu Việt Nam, phục hồi chức năng

\section{SUMMARY \\ YOGA THERAPY VIETNAM PROCESS ON REHABILITATING SEQUENCES OF CEREBROVASCULAR ACCIDENT PATIENTS}

Study on a randomized controlled clinical trial on 2 groups of patients to evaluate the results of Vietnamese yoga therapy in rehabilitation of patients with cerebrovascular accident. 80 patients with cerebral vascular accident sequelae were treated in stable acute phase, aged 40-75 years old, regardless of gender, occupation, and volunteered to participate in the study. 40 patients in the study group had their rehabilitation by the method of Vietnamese yoga therapy, and the control group had received conventional rehabilitation treatment. Compared results after 90 days of treatment showed that $75 \%$ of 
patients in the intervention group reduced 2 or more levels of paralysis, this rate in the control group was $42.5 \%(p<0.05)$. In addition, blood pressure, mental health, independence in daily activities, and risk of falling were statistically significantly better than before treatment and the control group.

Keywords: cerebrovascular accident, yoga, Vietnamese yoga therapy, rehabilitation

\section{I. ĐẶT VẤN ĐỀ}

TBMMN là nguyên nhân tử vong thứ hai trên toàn thế giới và là nguyên nhân hàng đâu gây tàn tật [3]. Bệnh có thể gây tử vong nhanh chóng hoặc để lại nhiều biến chứng nặng nề đặc biệt là di chứng vận động, không những gây ảnh hưởng nghiêm trọng đến sức khỏe lao động và cuộc sống người bệnh mà còn ảnh hưởng tới gia đình và xã hội. Ngày nay, với sự phát triển không ngừng của y học, các kỹ thuật PHCN đang được quan tâm ứng dụng cho người bệnh TBMMN và đã đem lại hiệu quả đáng kể [1]. Tuy nhiên, còn nhiều khó khăn để PHCN cho bệnh nhân di chứng TBMMN bằng các phương pháp hiện tại như: Thời gian PHCN kéo dài, các phương pháp trị liệu không được liên tục, khó luyện tập sau khi ra viện, tại cộng đồng. Sự chăm sóc của nhân viên y tế và người nhà cũng gặp nhiều khó khăn, thiếu nhân lực chăm sóc, gây tốn kém kinh tế cho bản thân, gia đình và xã hội. Trong thời gian ở nhà, hầu như bệnh nhân ít được tập luyện, bệnh nhân phụ thuộc nhiều vào các đợt điều trị tại bệnh viện. Tâm lý người bệnh luôn lo lắng, căng thẳng, stress, thậm chí trầm cảm.

Yoga trị liệu là một phương pháp khoa học cố xưa, để duy trì và cải thiện sức khỏe con người ở mọi khía cạnh. Nhiều nghiên cứu đã chứng minh tác dụng của Yoga trong $\mathrm{PHCN}$ cho người bệnh TBMMN cho thây sự cải thiện đáng kể khả nẳng thăng bằng và tốc độ dáng đi, tăng sự tự tin, giảm nỗi sợ hãi bị ngã xuống, tăng tầm vận động của các khớp, giảm các cớn đau nhức xương khớp [7], [4]. Đặc biệt, Yoga là liệu pháp bố sung cho PHCN tại cớ sở y tế và cộng đồng, người bệnh có thể tự luyện tập Yoga tại nhà một cách hiệu quả [5].

Nhận thây những vấn đề trên, các bác sĩ Bệnh viện Đa khoa thành phố Hà Tĩnh, trong quá trình học tập, nghiên cứu về Yoga trị liệu và các phương pháp PHCN hiện tại đã tạo nên một phương pháp điều trị mới là "Yoga trị liệu Việt Nam", tên viết tắt thường gọi là VinapYoga. Từ đó, các Thầy thuốc đã dần ứng dụng để phục hồi chức năng cho một số bệnh nhân tình nguyện mang lại hiệu quả rõ rệt. Chính vì những lý do trên, chúng tôi thực hiện đề tài với mục tiêu:
"Đánh giá kết quả phương pháp Yoga trị liệu Việt Nam trên bệnh nhân Di chứng tai biến mạch máu não tại Bệnh viện đa khoa thành phố Hà Tĩnh".

\section{II. ĐỐI TƯỢNG VÀ PHƯƠNG PHÁP NGHIÊN CỨU 1. Đối tượng}

- Đối tượng nghiên cứu. Người bệnh được chẩn đoán và điều trị di chứng TBMMN tại Khoa Phục hồi chức năng - Đông y, Bệnh viện đa khoa thành phố Hà Tĩnh từ tháng $1 / 2020$ đến tháng $6 / 2021$

\section{- Tiêu chuẩn lứa chọn}

+ Bệnh nhân di chứng TBMMN đã được chẩn đoán và̀ điều trị giai đoạn cấp ổn định. Hiện tại còn hội chứng thần kinh khu trú biểu hiện bằng các khiếm khuyết vận động, cảm giác, nhận thức, ngôn ngữ... ở các mức độ khác nhau;

+ Người bệnh tỉnh táo, tiếp xúc tốt;

+ Bệnh nhân đồng ý tham gia nghiên cứu.

- Tiêu chuẩn loại trừ

+ Có các biến chứng như loét, bội nhiễm;

+ Có bệnh lý nhiễm trùng nặng; suy tim độ II trở lên theo phân độ NYHA, mang máy tạo nhịp tim, rối loạn nhịp tim nặng, rung nhĩ; suy hô hấp, suy gan nặng, suy thận mức độ nặng; Ung thư' giai đoạn nặng, mù;

+ Bệnh nhân liệt do các nguyên nhân khác;

+ Bểnh nhân đang mắc các bệnh truyền nhiếm

+ Bệnh nhân không đồng ý tham gia nghiên cứu.

\section{Phương pháp nghiên cứu}

2.1. Thời gian, địa điểm nghiên cứu

+ Địa điểm nghiên cứu: Khoa Phục hồi chức năng - Đông $y, B V$ đa khoa thành phố Hà Tĩnh.

+ Thời gian nghiên cứu: từ tháng $1 / 2020$ đến tháng 6/2021.

2.2. Thiết kế nghiên cứu: Thử nghiệm lâm sàng ngẫu nhiên có đối chứng.

2.3. Cỡ mẫu và chọn mầu: Chọn mẫu ngẫu nhiên đơn

\subsection{Quy trình tiến hành nghiên cứu}

+Bước 1: khám sàng lọc tất cả người bệnh TBMMN vào khoa điều trị dựa trên tiêu chuẩn lựa chọn và tiêu chuẩn loại trừ.

+ Bước 2: sau khi khám sàng lọc, người bệnh nghiên cứu sẽ được đánh số thứ tự từ 1 đến 80 , trường hợp người bệnh bỏ cuộc hay bất kỳ lý do không tham gia nghiên cứu nữa sẽ tiếp tục lấy và đánh số đến khi đủ 80 người bệnh.

Dùng phần mềm Excel với hàm RAND() tạo bảng số ngẫu nhiên khối với số đối tượng trong mỗi khối là 40 . Sau phân bổ được xếp và bỏ vào bao thư đục dán kín và xếp theo số liên tục. Sau khi bệnh nhân đạt đủ chuẩn (tuyển vào, loại trừ) 
và ký giấy ưng thuận, bác sĩ nhóm nghiên cứu sẽ mở bao thư theo đúng số liên tiếp qui định sẵn và phân đối tượng vào nhóm.

Nhóm can thiệp (NCT): Điều trị bằng phương pháp VinapYoga và phác đồ nền.

Nhóm đối chứng $(\mathrm{NDC})$ : Điều trị bằng phương pháp $\mathrm{PHCN}$ và phác đồ nền.

Làm mù (Blinding): Đây là nghiên cứu mở không "làm mù"

+ Bước 3: thăm khám trực tiếp người bệnh để thu thập đầy đủ thông tin như đo huyết áp, mức độ liệt theo thang điểm mRankin, chức năng sinh hoạt hằng ngày theo Barthel, mức độ trầm cảm theo thang điểm Beck, rối loạn thăng bằng theo thang điểm BBS, đưa ra phác đồ điều trị phù hợp.

+Bước 4: hướng dẫn phương pháp VinapYoga (NCT) và phương pháp PHCN (NĐC).

+ Bước 5: đánh giá lại các chỉ số như ngày lần đầu sau 90 ngày điêu trị. Đối với trường hợp ra viện, người bệnh được hướng dẫn, phát tài liệu mang về, sau đó nhóm nghiên cứu thu thập số liệu, đánh giá kết quả dựa trên: tái khám tại bệnh viện (bằng phiếu hẹn tái khám gửi cho người bệnhh); gọi điện thoại và đến khám tại nhà người bệnh.

+ Bước 6: tổng hợp và phân tích số liệu thu được để tìm các biênn số có ý nghĩa đáp ứng các mục tiêu nghiên cứu. Cách ghi chép mẫu biểu, phân tích và xử lý số liệu theo một quy trình và phương pháp thống nhất.

2.5. Phương pháp xử lý số liệu: Các số liệu được xử lý theo phương pháp thống kê y sinh học bằng phần mềm SPSS 16.0. Các thuâat toán được áp dụng: tính tỷ lệ phần trăm, tính số trung bình, độ lệch chuẩn, T-Student để so sánh giữa 2 giá trị trung bình, Fisher exact để so sánh giữa 2 nhóm.

3. Đạo đức nghiên cứu. Nghiên cứu đã được UBND tỉnh Hà Tînh, Sở Khoa học \& Công nghệ công nhận kết quả đánh giá đề tài cấp tỉnh theo Quyết định số 1453/QĐ-SKHCN ngày 24 tháng 9 năm 2021.

Đề tài đã được báo cáo tại Hội nghị Hiệp hội Yoga trị liệu Châu Á (Asian Yoga Therapy Conference - AYAT) lần thứ 5 vào ngày 29 tháng 9 năm 2021.

Các đối tượng tham gia nghiên cứu là tự nguyện và có quyền rút lui khỏi nghiên cứu bất cứ lức nào. Các thông tin đối tượng cung cấp cho nghiên cứu là bí mật và chỉ phục vụ cho mục đích nghiên cứu.

\section{KẾT QUẢ NGHIÊN CỨU}

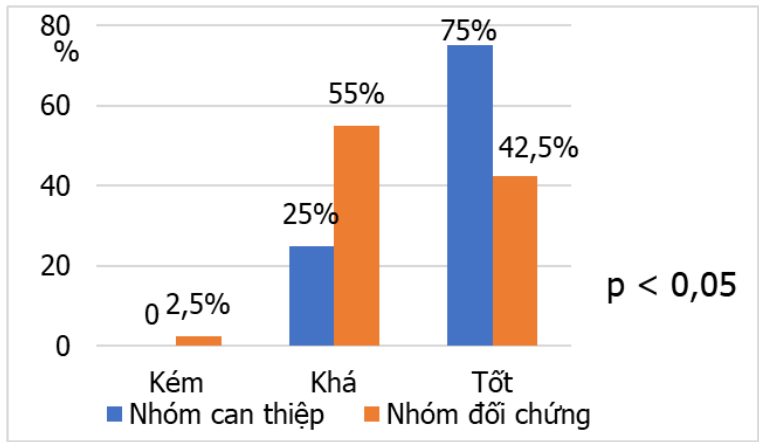

Biểu đồ 1. Hiệu quả phuc hồi chức năng dựa trên mức tiến triển độ liệt sau 90 ngày điều trị

Chúng tôi đánh giá hiệu quả PHCN dựa trên mức tiến triển độ liệt (theo thang điểm mRankin) sau 90 ngày điều trị so với thời điểm đánh giá đầu tiên. Dịch chuyển 2 độ liệt trở lên là tiến triển tốt, dịch chuyển 1 độ là tiến triển khá và không dịch chuyển là tiến triển kém. Qua biểu đồ 1 cho thây ở NCT có $75 \%$ người bệnh tiến triển tốt, $25 \%$ tiến triển khá và không có ai tiến triển kém, trong khi đó ở NĐC chỉ có $42,5 \%$ người bệnh có mức tiến triển tốt, $55 \%$ tiến triển khá và còn $2,5 \%$ tiến triển kém. Sự khác biệt này có ý nghĩa thống kê với $p<0,05$.

Bảng 2. Sự thay đổi mức độ độc lập trong sinh hoạt hằng ngày (thang điểm Barthel) sau 90 ngày điều trị

\begin{tabular}{|c|c|c|c|c|c|c|c|c|c|c|}
\hline \multirow{3}{*}{$\begin{array}{c}\text { Mức độ } \\
\text { phụ thuộc }\end{array}$} & \multicolumn{4}{|c|}{ Trước điều trị } & \multirow{3}{*}{$\mathbf{P}$} & \multicolumn{4}{|c|}{ Sau điều tri } & \multirow{3}{*}{$\mathbf{P}$} \\
\hline & \multicolumn{2}{|c|}{ NCT } & \multicolumn{2}{|c|}{ NĐC } & & \multicolumn{2}{|c|}{ NCT } & \multicolumn{2}{|c|}{ NDC } & \\
\hline & $\mathrm{n}$ & $\%$ & $\mathbf{n}$ & $\%$ & & $\mathbf{n}$ & $\%$ & $n$ & $\%$ & \\
\hline $\begin{array}{l}\text { Phù thuộc } \\
\text { hoàn toàn }\end{array}$ & 13 & 32,5 & 13 & 32,5 & \multirow{4}{*}{$>0,05$} & 0 & 0 & 0 & 0 & \multirow{4}{*}{$<0,05$} \\
\hline $\begin{array}{l}\text { Phụ thuộc } \\
\text { trung bình }\end{array}$ & 13 & 32,5 & 16 & 40 & & 0 & 0 & 5 & 6,25 & \\
\hline Phụ thuộc ít & 14 & 35 & 11 & 27,5 & & 8 & 20,0 & 10 & 12,5 & \\
\hline $\begin{array}{c}\text { Độc lập } \\
\text { hoàn toàn }\end{array}$ & 0 & 0 & 0 & 0 & & 32 & 80,0 & 25 & 62,5 & \\
\hline
\end{tabular}


Bảng 2 cho thấy sau 90 ngày can thiệp, ở cả 2 nhóm người bệnh đều có thay đổi tích cực ở sự độc lập trong sinh hoạt hằng ngày. Từ không có người bệnh nào độc lập hoàn toàn trong sinh hoạt ở cả hai nhóm đã tăng lên $80 \%$ ở NCT và $62,2 \%$ NĐC. Người bệnh phải phụ thuộc hoàn toàn ở từ 32,5\% ở cả 2 nhóm xuống còn không có người bệnh nào. Sự khác biệt trước và sau điều trị khi so sánh cùng nhóm có ý nghĩa thống kê $(p<0,05)$.

Bảng 3. Hiệu quả cải thiện nguy cơ té ngã (thang điểm BBS) sau 90 ngày điều trị

\begin{tabular}{|c|c|c|c|c|c|c|c|c|c|c|}
\hline \multirow{3}{*}{ Nguy cơ té ngã } & \multicolumn{4}{|c|}{ Trước điêuu trị } & \multirow{3}{*}{$\mathbf{P}$} & \multicolumn{4}{|c|}{ Sau điều trị } & \multirow{3}{*}{$\mathbf{P}$} \\
\hline & \multicolumn{2}{|c|}{ NCT } & \multicolumn{2}{|c|}{ NĐC } & & \multicolumn{2}{|c|}{ NCT } & \multicolumn{2}{|c|}{ NĐC } & \\
\hline & $\mathbf{n}$ & $\%$ & $\mathbf{n}$ & $\%$ & & $\mathbf{n}$ & $\%$ & $\mathbf{n}$ & $\%$ & \\
\hline Nguy cơ té ngã thấp & 18 & 45,0 & 19 & 47,5 & & 34 & 85,0 & 26 & 65,0 & \\
\hline Nguy cơ té ngã trung bình & 16 & 40,0 & 14 & 35,0 & $>0,05$ & 5 & 12,5 & 7 & 17,5 & $<0,05$ \\
\hline Nguy cơ té ngã cao & 6 & 15,0 & 7 & 17,5 & & 1 & 2,5 & 7 & 17,5 & \\
\hline
\end{tabular}

Bảng 3 cho thấy nguy cơ té ngã theo thang điểm BBS có xu hướng giảm sau 90 ngày điều trị ở cả 2 nhóm. Nguy cơ té ngã cao giảm từ $15 \%$ còn $2,5 \%$ ở NCT, tỷ lệ này không đổi ở NĐC. Nguy cơ té ngã trung bình giảm từ $40 \%$ còn $12,5 \%$ ở NCT và từ $35 \%$ xuống 17,5\% ở NĐC. Khác biệt tại thời điểm trước và sau 90 ngày điều trị khi so sánh cùng NCT có ý nghĩa thống kê $(p<0,05)$.

Bảng 4. Hiệu quả cải thiện huyết áp sau 90 ngày điều trị

\begin{tabular}{|c|c|c|c|c|c|c|}
\hline \multirow{2}{*}{ Nguy cơ té ngã } & \multicolumn{2}{|c|}{ Trước điêuu trị } & \multirow{2}{*}{ P } & \multicolumn{2}{|c|}{ Sau điêu trị } & \multirow{2}{*}{ P } \\
\cline { 2 - 3 } \cline { 5 - 6 } & NCT & NĐC & NCT & NĐC & \multirow{2}{*}{ P } \\
\cline { 2 - 6 } & Mean \pm SD & Mean \pm SD & & Mean \pm SD & Mean \pm SD & \\
\hline Huyết áp tâm thu & $137,8 \pm 13,3$ & $137,1 \pm 14$ & $>0,05$ & $127,6 \pm 9,7$ & $134 \pm 8,7$ & $<0,05$ \\
\hline Huyết áp tâm trương & $84 \pm 6,3$ & $84,5 \pm 8,4$ & $>0,05$ & $82,3 \pm 5,3$ & $86,5 \pm 5,3$ & $<0,05$ \\
\hline
\end{tabular}

Bảng 4 cho thấy huyết áp của người bệnh NCT có xu hướng giảm sau 90 ngày điều trị, tuy nhiên ở NĐC sự thay đổi này không đáng kể. Cụ thể, huyết áp tâm thu trung bình ở NCT giảm từ $137,8 \pm 13,3 \mathrm{mmHg}$ còn $127,6 \pm 9,7 \mathrm{mmHg}$. Huyết áp tâm trương trung bình giảm từ $84 \pm 6,3$ $\mathrm{mmHg}$ còn $82,3 \pm 5,3 \mathrm{mmHg}$. Khác biệt tại thời điểm trước và sau 90 ngày điều trị khi so sánh ở NCT có ý nghĩa thống kề $(p<0,05)$.

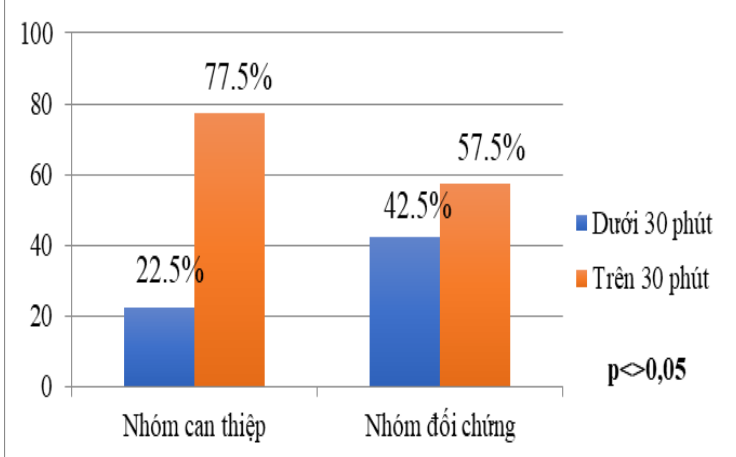

Biểu đồ 2. Thời gian luyện tập tại nhà giữa 2 nhóm người bệnh

Ở NCT, có $77,5 \%$ BN tập luyện tại nhà trên 30 phút, trong khi đó NĐC chỉ có $57,5 \%$. Sự khác biệt này có ý nghĩa thống kê với p>0,05.

\section{BÀN LUÂ̂N}

Yoga là một phương pháp đơn giản dễ học, dễ thích nghi và dựa vào cộng đồng, có hiệu quả cao về mặt kinh phí [2]. Có nhiêu bằng chứng cho thấy sự hiệu quả khi áp dụng tập yoga tại nhà cho bệnh nhân đột quy. [4]. Thời gian luyện tập tại nhà là yếu tố quan trọng trong $\mathrm{PHCN}$ cho người bệnh. Ngoài thời gian điều trị tại Bệnh viện, có nhiều BN không thể tiếp tục ở lại điều trị, hoặc nhiều BN thấy bệnh tình nhẹ hơn rồi xin ra viện, thì việc tập luyện tại nhà và cộng đồng rất quan trọng. Trong nghiên cứu của chúng tôi cho thấy có $32,5 \%$ người bệnh tập dưới 30 phút trên tổng số BN nghiên cứu, trong đó $22,5 \%$ BNNCT, 42,5\% NĐC. Có 67,5\% người bệnh có thời lượng tập tại nhà trên 30 phút, ở NCT có $77,5 \%$, NĐC $57,5 \%$. Sự khác biệt này có ý nghĩa thống kê Người bệnh ở NCT được tập các bài tập VinapYoga tại nhà, các bài tập tác động vào từng nhóm cớ, tăng sức mạnh của các cơ lõi (core), tăng tầm vận động các khớp, làm tăng khả năng thăng bằng, hỗ trợ tốt cho việc đứng, đi lại; hơn nữa, có một chế độ luyện tập phù hợp hằng ngày, có sự giám sát của CBYT cũng như nhắc nhở của người nhà, nên bản thân $B N$ ý thức được việc cần tập luyện thường xuyên nên mức độ cải thiện tốt hơn so với nhóm còn lại.

Kết quả nghiên cứu của chúng tổi cho thấy Yoga trị liệu Việt Nam có hiệu quả trong cải thiện mức độ liệt của người bệnh cụ thể ở NCT có $75 \%$ người bệnh tiến triển tốt, $25 \%$ tiến triển khá, trong khi đó ở NDC chỉ có $42,5 \%$ người bệnh có mức tiến triển tốt, $55 \%$ tiến triển khá, sự khác biệt này có ý nghĩa thống kê với $p<0,05$. Điều này cho thấy hiệu quả của phương pháp 
VinapYoga trong tập luyện tại bệnh viện cũng như tại nhà dưới sự giám sát của nhân viên y tế. Ngoài ra, đối với NCT, mức huyết áp trung bình vẩn giảm dần theo thời gian, cho thấy rằng việc sử dụng các phương pháp VinapYoga đã giúp kiểm soát tốt huyết áp. Trong chương trình can thiệp, chúng tôi tác động đến người bệnh cả thể chẩt lẫn tinh thần, việc tập trung vào sự cải thiện về tinh thần thông qua các bài tập thở, thiển định sẽ giúp cho BN ổn định tâm lý, có thêm niềm tin trong cuộc sống, từ đó người bệnh có thêm động lực để tập luyện. Mặt khác, trong quá trình điều trì, người bênh được tập các bài tập đơn giản, dễ nhớ, dễ hiểu và khi ra viện người bệnh được nhân viên y tế đưa ra kế hoạch tập cụ thể tại nhà nên người bệnh sẽ có ý thức trong việc tập luyện, từ đó nâng cao khả năng $\mathrm{PHCN}$ cho bản thân họ.

Dựa vào kết quả ở bảng 3.13 và bảng 3.14 chúng tôi thấy rằng, điểm trung bình nguy cơ té ngã theo thang điểm BBS ở NCT và NĐC đều tăng lên qua các thời điểm sau $15,30,60$ và 90 ngày điều trị. Điều này cho thấy cá quy trình tập PHCN truyền thống và VinapYoga đều giúp cải thiện khả năng thăng bằng của $\mathrm{BN}$. Tuy nhiên, ở NCT có khả năng thăng bằng tốt, giảm nguy cơ té ngã rõ rệt hơn, cụ thể, sau 90 ngày điểm trung bình 48,9 $\pm 11,6$; còn NDC là $42,8 \pm 16,6$, sự khác biệt có ý nghĩa thống kê $(p<0,05)$. Kết quả này trong nghiên cứu của chúng tôi tương đồng với nghiên cứu của Anupama Anant Paranjape năm 2019, cụ thể kết quả điểm trung bình của NCT sau khi tập luyện 12 buổi Yoga trong 3 tuần, thang điểm BBS tăng từ 41 lên 50 [8]. Một nghiên cứu về khả năng cải thiện thăng bằng của Yoga sau đột quy của Arlene $A$. Schmid và cộng sự (2012) cũng cho kết quả tương tự, điểm trung bình của thang điểm BBS tăng từ $41,3 \pm 11,7$ lên $46,3 \pm 9,1$ sau 8 tuần với 16 buổi tập [6].

Sau 90 ngày can thiệp, ở cả 2 nhóm người bệnh đều có thay đổi tích cực ở sự độc lập trong sinh hoạt hằng ngày. Từ không có người bệnh nào độc lập hoàn toàn trong sinh hoạt ở cả hai nhóm đã tăng lên $80 \%$ ở NCT và $62,2 \%$ NDC. Người bệnh phải phụ thuộc hoàn toàn ở từ $32,5 \%$ ở cả 2 nhóm xuống còn không có người bệnh nào. Sự khác biệt trước và sau điều trị khi so sánh cùng nhóm có ý nghĩa thống kê $(p<0,05)$. Qua nghiên cứu, chúng tôi thấy đa số người bệnh còn khó khăn trong khả năng tự leo cầu thang không vịn tay. Khi đã lên và xuống được bậc cầu thang, người bệnh có thể đã độc lập được trong các chức năng sinh hoạt hàng ngày, có thể hòa nhập với cộng đồng. Tuy nhiên, đây là động tác khó thực hiện và là một trong những chức năng chậm cải thiện nhất trong nghiên cứu của chúng tôi.

\section{KẾT LUÂ̂N}

Yoga trị liệu Việt Nam có thể được thực hiện tại các cơ sở y tế và cộng đồng, có thể tiết kiệm chi phí cho người bệnh, mang đến hiệu quả cao trong PHCN người bệnh TBMMN. Phương pháp VinapYoga giúp BN cải thiện độ liệt tốt hơn so với phương pháp $\mathrm{PHCN}$ truyền thống $(75 \%$ và $42,5 \%$ với $p<0,05)$. Khả năng giữ thăng bằng ở NCT cải thiện tốt hơn so với NĐC ( $85 \%$ và $67,5 \%$ với $p<0,05)$. Tỷ lệ người bệnh ở NCT có mức độ thực hiện sinh hoạt hằng ngày độc lập hoàn toàn $(80 \%)$ cao hơn có ý nghĩa thống kề so với NĐC $(62,5 \%)$.

\section{TÀI LIÊU THAM KHẢO}

1. Hưng Đ.Q., Giang L.M., Minh P.V. và cộng sự. (2021). Thực trạng các vấn đề sức khoẻ có cạn thiệp phục hồi chức năng tại một số bệnh viện tuyến tỉnh và tuyến huyên ở các vừng sinh thái việt nam. Tạp Chí Học Việt Nam, 503(1).

2. DiBenedetto M., Innes K.E., Taylor A.G. và cộng sự. (2005). Effect of a gentle Iyengar yoga program on gait in the elderly: an exploratory study. Arch Phys Med Rehabil, 86(9), 1830-1837.

3. GBD 2017 Causes of Death Collaborators (2018). Global, regional, and national age-sexspecific mortality for 282 causes of death in 195 countries and territories, 1980-2017: a systematic analysis for the Global Burden of Disease Study 2017. Lancet Lond Engl, 392(10159), 1736-1788.

4. Lawrence M., Celestino Junior F.T., Matozinho H.H. và cộng sự. (2017). Yoga for stroke rehabilitation. Cochrane Database Syst Rev, 12(1), 83.

5. Lazaridou A., Philbrook $P_{\text {., }}$ và Tzika A.A. (2013). Yoga and mindfulness as therapeutic interventions for stroke rehabilitation: a systematic review. Evid-Based Complement Altern Med ECAM, 2013, 108.

6. Schmid A.A., Miller K.K., Van Puymbroeck M. và cộng sự. (2014). Yoga leads to multiple physical improvements after stroke, a pilot study. Complement Ther Med, 22(6), 994-1000.

7. Schmid A.A., Van Puymbroeck M., Altenburger P.A. và cộng sự. (2012). Balance and Balance Self-Efficacy Are Associated With Activity and Participation After Stroke: A CrossSectional Study in People With Chronic Stroke. Arch Phys Med Rehabil, 93(6), 1101-1107.

8. Paranjape A.A. và Gore A. (2019). To Study Effects of Yoga Therapy on Balance in Post Stroke Hemiplegic Patients. Int J Health Sci Res, 9(7), 135-143. 